\title{
Integrity vs. Quality of Assessments: Are They Compromised on the Online Platform?
}

\author{
Leelakrishna Reddy ${ }^{1 *}$ (1), Machaba Leanyatsa Letswalo ${ }^{1}$ (1), Amanda Percy Sefage ${ }^{1}$ (1),

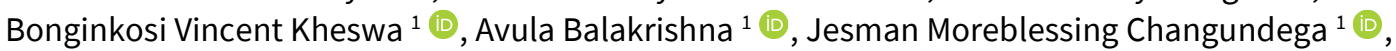 \\ Mashinga Johannes Mvelase ${ }^{1}{ }^{(\mathbb{C}}$, Khayelihle Allen Kheswa ${ }^{2}{ }^{(0)}$, Siyabonga Ntokozo Thandoluhle Majola ${ }^{1}(\mathbb{0}$, \\ Themba Mathe ${ }^{1}$ (i), Teffo Seakamela ${ }^{1}$ (i), Thendo Emmanuel Nemakhavhani ${ }^{1}{ }^{(0)}$
}

${ }^{1}$ Department of Physics, University of Johannesburg, SOUTH AFRICA

${ }^{2}$ Academic Development Centre, University of Johannesburg, SOUTH AFRICA

*Corresponding Author: krishr@uj.ac.za

Citation: Reddy, L., Letswalo, M. L., Sefage, A. P., Kheswa, B. V., Balakrishna, A., Changundega, J. M., Mvelase, M. J., Kheswa, K. A., Majola, S. N. T., Mathe, T., Seakamela, T., \& Nemakhavhani, T. E. (2022). Integrity vs. Quality of Assessments: Are They Compromised on the Online Platform?. Pedagogical Research, 7(2), em0121. https://doi.org/10.29333/pr/11840

\section{ARTICLE INFO}

Received: 3 Jan. 2022

Accepted: 17 Feb. 2022

\begin{abstract}
Integrity and quality of assessments on the online platform should be upheld to ensure that it supports student learning as well as the efficacy of teaching because in the end it measures the reputation of an institution. How institutions have traversed such domains remains a grey area. This paper provides anecdotal insights into how staff from a South African university have taken steps to mitigate against cheating to preserve integrity and quality of assessments. For this, a carefully designed survey with questions pertaining to integrity and quality of assessments were designed and administered to 11 physics staff members of the university. Results of the survey were presented and discussed both quantitatively and qualitatively. Results reveal that staff are serious about the integrity of assessments and have employed various techniques to combat it, but full proof integrity of assessments cannot be fully arrested on the online platform with proctoring and other strategic measures in place.
\end{abstract}

Keywords: integrity online platform, proctoring, quality, efficacy

\section{INTRODUCTION}

COVID-19 pandemic in 2020 has forced at least $90 \%$ of the universities around the world to move from face-to-face contacts to the online format (UNESCO, 2020). This was a crisis for which no one was prepared and put the facilitation of online offerings and assessments under the microscope (Gamage et al., 2020). With assessments under the spotlight, the new challenge faced by educators was the integrity of assessments especially for students not physically proctored by invigilators (Gamage et al., 2020). So, the question asked is why integrity of assessments is so crucial in this situation? For institutions of higher education, academic integrity is crucial for maintaining high standards and benchmarking, a requirement for university rankings. So, what is academic integrity? It is defined as follows: "a commitment, even in the face of adversity, to six fundamental values: honesty, trust, respect, responsibility, and courage" (Fishman, 2020; Gamage et al., 2020). These are necessary so that staff and students act in an "academically integrous manner" (Holden et al., 2021) when offences are committed and to uphold the reputation of an institution of higher education. Means that when degrees are conferred to a student, they should reflect the skills and knowledge that the student has acquired from such an institution that are reputable and the holder of such a degree should be proud of his/her accomplishments (Holden et al., 2021). Every higher education institution has some policy that relates to academic integrity but whether they are consistently followed is a grey area (Gamage et al., 2020). In this respect, academic staff may "lack consensus about what constitutes academic misconduct, which results in certain acts of academic misconduct going undetected" (Gamage et al., 2020). Further, the challenges of online teachings and other commitments of staff, such as research, supervision, and the tedious process of documentation of evidence could be overwhelming that could cause them to overlook cheating. This misdemeanor of academic misconduct by staff could compromise the quality of degrees offered and the reputation of an institution. The lack of invigilation proctoring may lead students to seek assistance from friends and freelancers to do the work for them (Gamage et al., 2020). Issues of student verification and identification provides further opportunity for a third party to take an assessment on behalf of the student (Gamage et al., 2020). No technology is full proof enough to detect online cheating as students have found unique and innovative ways of beating the system.

For subjects like STEM fields of study compared to other subjects poses more of a challenge for lecturers to teach remotely because of its dependence on hands-on experience and empirical knowledge (Gamage et al., 2020) and for the students to come 
to terms with content knowledge, hence the possibility of academic misconduct and the pressure to do well. This study is guided by two research questions:

1. What measures lecturers have undertaken to mitigate against online cheating?

2. How have these measures safeguarded integrity and quality of assessments?

\section{LITERATURE REVIEW}

Academic misconduct which makes use of unauthorized materials, seeking help from others, falsification of self and plagiarism where one student has an edge over another student are undesirable behaviors on the online platform (Akbulut et al.,2008; Holden et al., 2021; Sendag et al., 2012). There are reasons why students deviate from integrous behaviors, and they are as highlighted by Holden et al. (2021) in the paper: "Online delivery and assessment during COVID-19: Safeguarding academic integrity":

1. Individual factors: According to Becker et al. (2006), three factors are necessary for cheating to occur: opportunity, incentive, and attitude. Opportunity takes place when the lecturer blankly overlooks cheating taking place and therefore allows the student to the grab the opportunity to cheat with no fear of being caught. The desire of the student to get good grades and compete with his/her friends and to be successful is an incentive to cheat. The attitude by a student to cheat is perceived as normal and perceived by them to be within the bounds of normal ethical behavior.

2. Institutional factors: According to Tolman (2017), there might be a culture prevalent in some universities that they can get away with cheating and for them to succeed, they must cheat as it is normal within such universities to perform such behaviors.

3. Medium of Delivery: According to King et al. (2014) and Watson and Sottile (2010), there is a higher prevalence of cheating on the online platform compared to in campus assessments of tasks. This begs the question whether online assessments are reliable enough to determine mastery of concepts. Researchers have shown that up to $47 \%$ of students were caught cheating in hard sciences (Lanier, 2006).

4. Assessment specific factors: This factor relates to cheating in various types of assessments. According to Watson and Sottile (2010), for in campus assessments, students appeared to cheat normally in assignments but in the case of online assessments, students were found to be cheating in tests or quizzes (23.2\% to $18.1 \%)$. Further, it was observed that if students were given the opportunity to cheat, they would cheat mainly in high stake summative assessments rather than formative assessments.

On the other hand, according to Cluskey et al. (2011), for "non-proctoring alternatives to online assessments" (Holden et al., 2021), the following has been suggested:

1. Offering of exams for a limited time period,

2. Offering of random sequence of questions,

3. Presenting questions, one at a time, instead of the entire paper, and

4. Imposing of lockdown browsers.

Other forms of cheating called "contract cheating" is gaining popularity on the online platform. "Contract cheating" occurs when students outsource their work to a third party and claim it is their own work (Fishman, 2016). Now third-party constituencies are people or companies that either do the work or outsource the work given to them for a monetary gain. This transfer of duties from one to another are called "essay mills". Services of "essay mills" are "lab reports, reflective journals, dissertations, computer programming, film editing, and other services" (Gamage et al., 2020). All these services pose a threat to academic integrity of an institution and may be very hard to detect.

Practical steps undertaken by the UK institutions of higher education to mitigate against academic misconduct are (Gamage et al., 2020):

1. Limitations imposed on recycling of previous assessments,

2. Effective training of invigilators,

3. Awareness of the consequences of cheating, and

4. Having a good room etiquette and procedures in place.

It must be noted that even though those students are aware of the risks of academic dishonesty, they still engage in such activities. One reason postulated by Gamage et al. (2020) is got to do with academic staff who do not spend enough time with curriculum design. For example, staff may take questions verbatim from a textbook without modifying it and this may result in students engaging in mischievous behaviors such as "googling" for answers from the internet. Other reasons for such behaviors are that students are under high pressure to do well arising from the competitiveness of the job market (Gamage et al., 2020) or to compete with peers in performance or the high cost of education compels them in doing such mischievous deeds.

Students obtaining grades from non-integrous behaviors can reflect false grades obtained from formative or summative assessments, thus impacting on the quality of the assessment. It will reflect false impression of the student's work, which is not commensurate with quality judged against fixed standards (Sadler, 2012). 


\section{METHODOLOGY}

Some background information about this research is that it involves South African students. As compared to many poor students around the world, these students are subsidized by the government for free education, free laptops, and daytime and nighttime data for the Internet usage. The only issues experienced by these students is perennial loadshedding and connectivity at times. It is against this backdrop that this research is conducted from the perspective of their lecturers. This research paper analyses the various steps lecturers have undertaken in safeguarding the integrity of assessments on the online platform to ensure quality of assessments. To achieve this, a carefully designed questionnaire of both qualitative and quantitative nature, consisting of questions pertaining to integrity and quality of assessments has been administered to 11 lecturers in the Department of Physics at the University of Johannesburg (Table 1). Prior to the administration of the questionnaire, permission was sought from them for this research. Questions from this questionnaire ranged from the nature of the course offerings, measures to mitigate against online cheating to success of their interventions. Lecturers were given sufficient time to complete this lengthy questionnaire and discussions and analysis of their inputs is the thrust of this paper. The participants' names will be categorized from letters A to I.

Table 1. Questionnaire outputs

\section{Course offerings}

Is your assessment continuous for the whole year and your examination mark is the same as the year average or continuous

assessments and a summative examination at the end?

Mainly consists of continuous or a combination of continuous assessments and a summative assessment at the end.

\section{Test assessments/examination assessments}

Steps taken to eliminate dishonesty

A: Use of different materials to set assessments with time limits.

B: I set questions that students can't find on the internet but hard for themselves.

C: Enforcing rules for assessments.

D: Use Invigilator App to invigilate assessments. Modify problems obtained from textbooks. Test setting on Blackboard that randomizes answers and problems, forbids backtracking, limited duration, starting time frames, etc.

E: Use a proctoring system and, also rely on numerous functionalities made available (i.e., putting time-limitations to answering questions, question randomization, prohibition of backtracking, refrain using questions taken verbatimly from publishers, offer different versions same task, variation of variables, etc.)

F: Students write at the same time, penalty for late submission. Question papers are protected such that students do not easily copy and paste a question to someone during a test. The test is sent with a passcode or opened at a defined time. There is only one chance to write a test for all and during marking I download their answers and save in one folder to identify those who submitted blank sheets and inform them before marking. I don't mark online to avoid getting feedback before marking all received scripts and getting a clear picture of who wrote and who did not write. They are first year students, I also emphasize on the consequences of cheating at the university and build strong relations with them, this makes students feel that I am always there for them. Keep reminding them about the importance of honesty and integrity policies of our university.

G: Using the UJ invigilator App to, for instance, catch people who discuss the test while writing. I also create new questions that do not have solutions on Google.

$\mathrm{H}$ : Use the Invigilator App. Rephrase and re-word questions taken from textbooks. Scramble the questions. Prohibit backtracking. Allow one question on screen at a time.

Did steps undertaken to eliminate dishonesty in the above lead to success?

A: Yes.

B: Yes, good students were found and who showed understanding of the work.

C: Partly yes, although a lot more is needed to eliminate dishonesty that comes through using multiple devices for online assessments and from discussions with peers.

D: Yes.

E: Yes.

F: Yes, to some degree.

G: I cannot guarantee that it worked $100 \%$, however, students' scripts submitted for tests had nothing suspicious. Since we encourage students to show their full steps that assists as well. Rules were emphasized, I even had a section on Blackboard where I uploaded UJ rules so that they were aware of their actions if they cheat.

$\mathrm{H}$ : To some degree yes, it did improve the academic integrity of result to a reasonably acceptable level. I:Yes.

Do you use any apps for your assessments? If yes, explain and would you recommend it to others?

A: No.

B: Yes, students would scan their work using their app.

C: Invigilator app, yes, I would recommend it even if it does not help $100 \%$.

D: Yes.

E: No, but I would like to try invigilator app for invigilation in the future.

F: Yes, I used the UJ invigilator app. I highly recommend it to others. The reason being I have been able to catch many students who discussed my assessment while they were writing. I believe that it also psychologically controlled students during assessments and made them feel like they are in an examination room.

G: Yes, I used the invigilator app and I would recommend it to others. I use Blackboard.

I:Yes, I used Blackboard as the test platform and the invigilator app as the proctoring software. I would recommend them both because to a large extent they do provide some levels of assessments with integrity.

Are students given a time limit to answer questions? Explain 
Table 1 (Continued). Questionnaire outputs

C: Yes, all tests written during a 2-hour period.

D: Yes.

E: Yes, they are. Students have an option to submit on Blackboard or send work through email. Instructions are clear that if they submit after a certain time, there is a penalty.

F: No, not for each question. They are given say $1.5 \mathrm{hrs}$ for the entire assessment and it is up to them how much time they spend on each question. However, all questions have the same weight. Hence students are likely to spend same amount of time on each question.

G: No, they are not given specific time to answer specific questions if they finish the entire assessment within the allocated time.

$\mathrm{H}$ : Yes, to prevent students from having enough time to search for answers (e.g. the Internet).

I: Yes, for example, 10 multiple choice questions (MCQ) test, a time of $1.5 \mathrm{hrs}$ is allocated.

Are students given more than one opportunity to answer a test? If yes, how many attempts are given?

\section{A: No.}

B: No, I give them one attempt, but before they write, I give them multiple tutorial test to prepare.

C: Yes, 2 attempts are given but it creates a havoc, because some students miss use the attempts by trying to upgrade their marks.

D: Yes.

E: Yes, with regards to assignments.

F: No.

G: Students are afforded 2 attempts. The $2^{\text {nd }}$ attempt was supposed to be taken only if/when there are connectivity issues during assessments.

$\mathrm{H}$ : One attempt.

I: No, they are given one opportunity. They are further given opportunities to make up for test if they did not do so well. These are scheduled sometimes later when hopefully these struggling students have had time to catch-up on understanding the concepts they were struggling with.

\section{If you gave MCQ questions, did you have a pool of them? Are students answering different questions from each other for the same} test?

A: No, switched to long questions.

B: No, students answer the same questions, but they were randomized.

C: No.

D: Yes, students were answering different questions from each other.

E: Yes, I don't like to give MCQ anymore. This approach needs to pick questions to allow a good choice during randomization process. I think to have a balance, one needs to have a section for MCQ and long questions, thereafter, I create questions that are graded as easy, medium, and challenging; otherwise, randomization might only place easy questions for some students and challenging ones for others.

F: No, they answer the same questions but in random order, many possible answers make it difficult for them to randomly choose an answer.

G: No.

$\mathrm{H}:$ No.

I: No, all students answer the same test. Yes, I personally have a slowly growing pool of problems for the module I am currently teaching.

For MCQ questions, do you pose options such as "none of the above", "all of the above", or a permutation of answers or you avoid such questions at all?

A: No.

B: No.

C: Yes, I use the 3 options.

D: I provide a permutation of answers.

E: No, direct options.

F: Yes, all options.

G: Yes, I do use options such as "none of the above" and "all of the above", but very infrequently.

H: Yes.

I: I do provide the answer "none of the other answers is correct" as one option in pretty most of my problems. I have so far avoided the other options that have a potential of having more than one correct answer.

Do you design your own questions (long questions) or modify existing questions? Explain and give one example.

A: Yes, modify existing questions.

$\mathrm{B}$ : Yes, I design and modify existing questions. For example, instead of giving the student a beam diagram for shear force and bending moments, I give them a statement where they will analyze the statement and determine the shear force or bending moment of the beam when subjected to multiple forces.

C: Yes, I modify existing questions i.e., such as explain, describe, etc.

D: I do both.

E: I modify existing questions such that it is not easy to pick it up and use different sources to draw questions from.

F: Yes, I modify questions from the textbook. I modify the wording of the problem statement, values of physical quantities, sometimes I ask them to compute a different quantity and not the one asked in the textbook.

G: I do both. Existing questions (from textbook) are always modified (rephased and reworded) and values changed.

$\mathrm{H}$ : Yes, I modify existing questions.

I: I usually modify pre-existing problems that I get from the textbook. See example seen later.

For long questions: Do you apply Bloom's taxonomy and ask questions such as explain, apply, analyze, extrapolate, synthesize, etc.? A: No.

B: Yes.

C: Yes.

D: Yes. 
Table 1 (Continued). Questionnaire outputs

E: Yes, I apply it. Questions are given such that some will ask the student to define concepts, explain the difference between concepts, to analyze a scenario. A question on momentum, work, and energy, I could ask a student to find the total energy and based on their calculations to make a conclusion on the type of collision that object experience.

$\mathrm{F}:$ Yes, I use questions such as "analyze", etc.

G: Yes.

H: No.

I: While on online teaching, I have not used long questions. I have used MCQ questions only.

Are students given a code to access their assessments?

A: No.

B: No.

C: No, but sometimes just to confuse them not to copy answers from another group who wrote the test earlier in the day, a password is given.

D: Yes.

E: Yes, there is a password code which is opened and closed at a defined time.

F: No.

G: No.

$\mathrm{H}$ : Yes.

I: Yes, a code for invigilator app is provided.

If students are found copying, what is your stance on the matter?

A: Take up the matter with HOD and notify their department. That is the only way to signal their cheating is totally unacceptable.

B: By enforcing examination rules and regulations, which can only be enforced if there is proof.

C: I gather evidence and take it further.

D: At this stage, adjudication on such a matter remains a challenge as it involves a lot of complexities. In effect, to date, this matter remains an uncharted territory in many institutions and needs to be looked at more closely.

E: Even though the situation forced to be online, I believe that rules remain, the assessment policy states clear rules that cheating is an offence. I will not hesitate to report the matter. That is why I made students aware of such rules and uploaded them separately on Blackboard.

F: Disqualify them and give them a choice to write a different test.

G: No comment.

H: No comment.

I: For tests, the student is disqualified and is given another opportunity to write another test. For exams, I follow UJ policies for assessment transgressions.

\section{Exam cheating is a "global issue", what would you suggest for mitigating against such occurrences and do you think you can win on} this matter?

A: This must be a very punishable offence, as we look for ways to mitigate cheating, the students are looking for new ways to cheat. B: To avoid this, allow students to write all assessments on campus, and you can only win if there is concrete evidence that the student has cheated.

C: Yes, with invigilator app, I think we can win.

D: Just as it remains a challenge even in contact/in-person exams, this matter pertaining to academic integrity cannot be arrested entirely. However, through stringent measures (such as deploying refined versions of the proctoring apps, which seek to improve the weaknesses of the functionalities of the current invigilator app), it can be better managed to an acceptable level.

E: With most institutions now offering now offering online exams, issues of cheating is still going to remain. The best way to deal with it is to have tests on campus instead of online. If students write in their private space, there is no way to win on this issue. Hopefully application apps like invigilator app will try to reduce cheating.

$\mathrm{F}$ : The best way is to have a webcam in front of each student who is writing remotely, divide big groups into smaller groups and assign one invigilator to each group, and use proctored assessments. This way we can win but it is probably expensive for the student to purchase. In the present economy, I do not think is winnable, it is better to have on-campus assessments. Only developed countries can win on this matter.

G: No comment.

H: No comment.

I: It can be fully achieved via full proctoring but given the financial stress on most South African universities, I do not think we can arrest the situation fully.

\section{DISCUSSION OF THE RESULTS}

\section{Course Offerings Since the Pandemic}

Most participant in the survey have indicated that their course offerings were of a continuous nature, meaning that the averages of all assessments that took place during the year replaced the summative examination that normally took place at the end of the year. Ever since the onset of the COVID-19 pandemic, most staff of the university opted for the "continuous" mode of assessments. A few have chosen a mixed mode of operation, both continuous and an examination type of assessments.

\section{App Used for Online Teaching at the University}

Most participants of the University have used the App Blackboard for the teaching of their online courses. This App is effective in that it allows for interactive discussions to take place, and in most instances can be used as a typical "chalkboard" that one uses for on campus teaching. This is particularly useful when one is required to explain the various steps involved in the derivation of physics formulas. It is also most effective for multiple choice questions (MCQ) type of assessments. 


\section{Measures Undertaken to Safeguarding the Integrity of Assessments on the Online Platform}

There were various measures undertaken by the participants of this survey in overcoming integrity of assessments. Participant $B$ has indicated that his students would find it hard to search for answers from the internet, meaning that either the wording of the question or the variables of the question had been changed or modified so that it would be difficult for students to find a match in the Google search engine. Participants D, G, H, and I were using the Invigilator App for invigilation of their assessments. This tool has been designed to assist lecturers in mitigating against offences for assessments on the online platform via the mobile network. Participant $D$ says that he modifies problems taken from the textbook, and he further indicates that he does the following to mitigate the risk of academic dishonesty:

1. Randomizes the answer options (in MCQs),

2. Forbids backtracking of answering questions, and

3. Gives a limited time for students to answer questions; otherwise, they might spend the extra time to share their answers with their peers.

In the case of participant $\mathrm{E}$, he also prohibits the backtracking of answering questions, gives a limited time for answering of questions, and he also makes use of advanced functionalities of Blackboard to safeguard risks of students cheating. He further refrains from taking questions verbatim from the textbook, which would otherwise allow students search for answers on the internet. Also, he indicates that by changing the variables of a problem, he could make googling of answers a bit problematic. Participant F first and foremost emphasizes the university's rules pertaining to cheating and copying and the consequences thereof to his students. He sends tests with a protected password and lets students start and end assessments at a set time, with penalties for late submissions. He also indicates that answers to assessments are not provided until all students are accounted for, this practice is to refrain students from submitting answers whilst the lecturer does a thorough post-mortem of the test in class. According to participant $\mathrm{H}$, whilst also being aligned with other participants, she allows for one question at a time to be displayed on the screen and combined with the prohibition of question backtracking, leaves no time for students to discuss answers with their peers.

\section{Did Steps Undertaken to Eliminate Dishonesty Lead to any Success in your Groups?}

On compiling learner guides at the University, lecturers have included a section called plagiarism. At the beginning of the semester, lecturers are expected to read and inform students about the importance of plagiarism and the consequences thereof. Students are then expected to sign a tear-off slip at the end of the guide, acknowledging that they have read and understood the rules and its implications. This is quite like the "honor" code of ethics that is practiced at most international universities. In this survey, most participants have indicated that the steps that they have undertaken to mitigate against online cheating were successful to some degree of understanding. Several participants have indicated "yes" with no reasons at all. Whilst these rules are available in the learner guides and which are also uploaded on Blackboard, one participant further goes on to say that he always makes students aware of the actions they potentially could face when caught cheating and to deter them from such nonintegrous behaviors. Participant $\mathrm{G}$ has indicated that students must show all steps in their calculations, the reason for this is that if a solution of a verbatimly copied solution is available on the internet, the lecturer could track the similarity in the way the solution has been presented. This is for the same reason why so many lecturers are opting for modifying exiting problems from the textbook. Designing novel problems is a skill and only comes with experience, because in designing such problems, one must ensure that the problem is soluble, practical, and realistic and conforms to fundamental laws of physics.

\section{Are Students Given a Time Limit to Answer the Questions? Explain}

Initially the confusion at the onset of online teaching, universities were sympathetic of students coping with assessments, and therefore were given more time to submit their assessments. Unfortunately, this has led to non-integrous behaviors, such as copying, sharing of answers, googling for answers, etc. A survey done almost 2 years into online assessments, lecturers have had to re-think at assessments especially in safeguarding the reputation of their institution, and hence the issue of time limit has become a contentious issue. All but one participant has indicated that they impose a time limit for assessments, and in one case, a penalty is awarded for late submission. All this is done to prevent students from cheating, as students have found novel ways to do so.

\section{Are Students Given more than One Opportunity to Answer a Test? If Yes, How Many Attempts are Given?}

As mentioned earlier, this was done to assist students in coping with online assessments. At least $50 \%$ of the participants have indicated that they gave their students one attempt. One participant $(\mathrm{G})$ has indicated that he gives a second attempt if there were connectivity issues during the online assessments. Participant $\mathrm{F}$ is also sympathetic with student performance and gives those that have performed badly an opportunity to improve their grading, which contradicts the way participant $C$ treats assessments of grade improvements. In terms of integrity, students with a second attempt opportunity, may seek help from those that have done the assessment in their first attempt, and it defies the purpose of this opportunity.

\section{If You Give MCQ Questions, Do You Have a Pool of Them? Are Students Answering Different Questions from Each Other for the Same Test?}

The online process is new for all staff and hence having a pool of MCQ type questions might be a bridge too far. All participants have indicated that they do not have a pool of questions for MCQ type of assessments. But what is very interesting to see is that most are opting for randomizing of the answers as a way forward. Participant $E$ is of the view that in randomizing answers, options may be pitched towards easy type of questions, while participant F says that having many options to MCQ type of questions will 


38 - CP An oil tanker's
engines have broken down, and
the wind is blowing the tanker
straight toward a reef at a con-
stant speed of $1.5 \mathrm{~m} / \mathrm{s}$ (Fig.
P38). When the tanker is $500 \mathrm{~m}$
from the reef, the wind dies
down just as the engineer gets
the engines going again. The rudder is stuck, so the only choice is
to try to accelerate straight backward away from the reef. The mass
of the tanker and cargo is $3.6 \times 10^{7} \mathrm{~kg}$, and the engines produce a
net horizontal force of $8.0 \times 10^{4} \mathrm{~N}$ on the tanker. Will the ship hit
the reef? If it does, will the oil be safe? The hull can withstand an
Figure P38
$\quad F=10^{4} \mathrm{~N} \quad \mathrm{v}=1.5 \mathrm{~m} / \mathrm{s}$
$\quad 3.6 \times 10^{7} \mathrm{~kg}$

Figure 1. Textbook version

make it difficult for some students to answer. This approach has allowed staff to re-imagine the future offerings of say "blended" learning approach to teaching. Participant I have initiated the process of slowly building up a pool of questions. In terms of integrity and quality of assessments, by randomizing of MCQ answers, would allow students to "falsely" cheat, which could unknowingly preserve cheating. In terms of quality of assessments, some of the best questions could be assessed by MCQ type of questions if strategized in a proper manner, having distractors that requires insightful thinking, otherwise it could be a meaningless exercise whereby students merely guess answers for the sake of answering it. The best option is to allow groups of students to answer a certain lot of questions, and this would largely prevent cheating, since no student is aware of what the other group is answering. For this question in the survey, $30 \%$ of the participants did not go for such distractors but followed a standard 3 to 4 distractor options. Another $50 \%$ of the participants are following the options as indicated in the survey, the advantage of using this option is to allow the lecturer of putting more effort into setting of questions of such a nature. An avid student is quickly looking for an easy option by choosing an easy distractor. Having a question with more than one answer of "none of the other answers is correct" (participant I) requires insightful thinking and puts testing of a concept at another level of understanding. In terms of integrity, if students are unsure of the options, it will be difficult for them to share it and at the same time ensures some degree of quality in assessments.

\section{Do You Design Your Own Questions (Long Questions) or Modify Existing Questions? Explain and Give an Example}

The purpose of asking this question was to ascertain if standard textbook questions are asked in assessments and if that is so, then students can easily google for answers from the Internet (Figure 1). Every problem in every physics textbook has a solution on the Internet, so it would defeat the purpose of testing understanding of a section/concept in assessments and it would also denigrate the quality of assessments. In this survey, most participants have modified problems from the textbook (Figure 2). One participant (F) says that he modifies the wording, the values of the physical quantities and sometimes asks them to compute other variables not asked from a standard problem. An example of a modified problem illustrated by participant I shows the shift from how it is presented and how it is asked in the assessment. Whilst this section focusses on both quality and integrity of assessment, it also indicates that students would find it difficult to google for answers from the Internet.

\section{Long Questions: Do You Apply Bloom's Taxonomy and Ask Questions such as Explain, Apply, Analyze, Extrapolate,} Synthesize, etc.?

In asking lower order questions, as categorized by Bloom's taxonomy, would be counterproductive in assessing higher order conceptual understanding of a particular section. By asking students to explain, discuss, extrapolate, analyze would test higher order thinking and is a requirement for students at a tertiary level. However, few marks may be asked at a lower level for a baseline understanding of the section. Further, in terms of integrity, it would be easy to catch students who have cheated in the way they have explained to resolve a problem. In terms of the survey, all but 2 participants have indicated that they practice it as a norm in their daily practices. However, not many have elaborated how it is done except participant $E$, who says that he asks questions such as:

1. Explain the differences between concepts,

2. Make a conclusion from the calculation, and

3. Describe the nature of the collision (for momentum type problems).

In one scenario, participant I indicate that since the onset of online offerings, she only focused on MCQ type of questions (maybe because of the ease of marking). 
2. The engines of a vessel at sea stop working and the vessel continues being pushed on by the wind at a steady speed of $\mathrm{v}=1.75 \mathrm{~m} / \mathrm{s}$. The seamen then notice that they are heading for rocks $700 \mathrm{~m}$ away as illustrated in Diagram L.

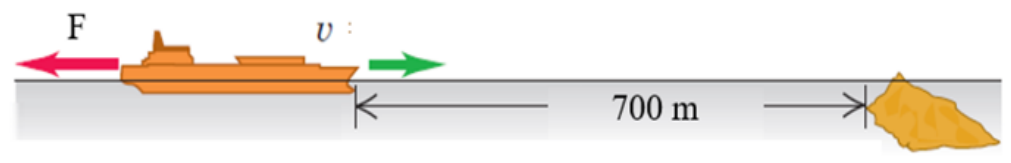

Diagram L

Fortunately, the engines are fixed that very moment and the seamen decide to immediately reverse away from the rocks. If the vessel of total mass 38 million kilograms experiences an engine's stopping force of magnitude $\mathrm{F}=84000 \mathrm{~N}$, will the vessel still collide into the rocks?

A. Yes, it will definitely collide into the rocks

B. No, it will stop several metres before the rocks

C. No, it will manage to stop just a few metres from the rocks

D. More information is needed

Figure 2. Edited version

\section{Are Students Given a Code to Access the Examination?}

At least $50 \%$ of the participants have indicated that a code is provided for them to do so. In general, a code is given to improve the integrity of assessments, whereby a third party would not answer it from another location on behalf of the student. In some cases, codes are provided, and the duration of the assessments is "timed" out. Also, the invigilator app with a QR code is created to preserve the integrity of the assessment, whereby a student would find it difficult to share answers.

\section{If Students are Caught Copying, What is Your Stance on the Matter?}

Participants views on cheating is mixed. Except for 2 participants that did not comment on this issue, the rest of them diligently followed the university transgression policy. There is also much red tape on this matter, and some find it cumbersome to pursue this matter all the way for student expulsion. Others take a more proactive route in disqualifying the student from a particular test and afford another opportunity for the student at a later stage. But the same person is strict with examination transgressions, whereby she enforces the examination policy. Some may argue that for transgressions on the online platform, rules pertaining to it may have to be relooked at it compared to on campus transgression, as this may bring litigation charges by the student. By and large majority of the participants are taking some actions on this matter and this bodes well for quality and integrity of assessments.

\section{Examination Cheating is a Global Issue, What Would You Suggest for Mitigating Against such Occurrences and Do You Think We Can Win on This Matter?}

Most participants are of the view that this situation in terms of examination cheating cannot be fully arrested, certain measures such as the invigilator app used for assessments proctoring could for the moment be the way forward. The app has drawbacks in its functionalities; students must take a selfie of themselves is not sufficient to prevent a third party from quietly doing the assessment on behalf of the student. One participant has indicated that if the app could be improved then it could be one way of managing online assessments. Most participants are happy to have students attend campuses for assessments only. Participant $\mathrm{F}$ is of the view that a webcam placed in front of the student would be a better way forwards, for small groups of students, with one staff allocated per group for invigilation. However, acquiring such a device bearing in mind the economic situation of South African students might be a bridge too far. Hence the views of the participants from the above discussions, it is very clear that integrity of assessments cannot be fully arrested, no matter what contingency steps are taken.

\section{CONCLUSIONS}

The use of Invigilation app, presenting one question at a time on the screen, the avoidance of backtracking, randomization of answers in MCQ type of assessments, and modification of questions from the textbook are some of the primary steps taken by the participants in safeguarding the integrity of assessments on the online platform. Most participants are enforcing the university's transgression policy when students are caught cheating for the examinations. Some maybe fearing the red tape that goes with collecting evidence pertaining to student cheating, leading to the expulsion of the student due to the extended workload presented by online teaching. No matter what strategy is put in place to mitigate against online cheating, this matter may not be fully arrested, and this could subsequently affect the quality of teaching that is presented for the first time on the online platform.

Author contributions: All authors have sufficiently contributed to the study, and agreed with the results and conclusions.

Funding: No funding source is reported for this study.

Declaration of interest: No conflict of interest is declared by authors. 


\section{REFERENCES}

Akbulut, Y., Sendag, S., Birinci, G., Kilicer, K., Sahin, M. C., \& Odabasi, H. F. (2008). Exploring the types and reasons of internettriggered academic dishonesty among Turkish undergraduate students: Development of internet-triggered academic dishonesty scale (ITADS). Computers and Education, 51(1), 463-473. https://doi.org/10.1016/j.compedu.2007.06.003

Cluskey, J., Ehlen, C., \& Raiborn, M. (2011). Thwarting online exam cheating without proctor supervision. Journal of Academic and Business Ethics, 4, 1-7.

Fishman, T. (2014). The fundamental values of academic integrity. The International Center for Academic Integrity under Creative Commons Attribution-Non-Commercial-ShareALike 4.0 International. https://www.academicintegrity.org/wp-content/ uploads/2017/12/Fundamental-Values-2014.pdf

Gamage, A. A. K., de Silva, E. K., \& Gunawardhana, N. (2020). Online delivery and assessment during COVID-19: Safeguarding academic integrity. Education Sciences, 10(301), 1-24. https://doi.org/10.3390/educsci10110301

King, D. L., \& Case, C. J. (2014). E-cheating: Incidence and trends among college students. Issues in Information Systems, 15(1), 2027. https://doi.org/10.48009/1_iis_2014_20-27

Lanier, M. M. (2006). Academic integrity and distance learning. Journal of Criminal Justice Education, 17, 244-261. https://doi.org/ $10.1080 / 10511250600866166$

Olivia, L., Meghan, E., Norris, Valerie, A., \& Kuhlmeier. (2021). Academic integrity in online assessment: A research review. Frontiers in Education, 6(14), 1-13. https://doi.org/10.3389/feduc.2021.639814

Sadler, D. R. (2012). Assessment, evaluation, and quality assurance: Implications for integrity in reporting academic achievement in higher education. Education Inquiry, 3(2), 201-216. https://doi.org/10.3402/edui.v3i2.22028

Sedag, S., Duran, M., \& Robert Fraser, M. (2012). Surveying the extent of involvement in online academic dishonesty (e-dishonesty) related practices among university students and the rationale students provide: One university experience. Computers in Human Behaviors, 28(3), 849-860. https://doi.org/10.1016/j.chb.2011.12.004

Tolman, S. (2017). Academic dishonesty in online courses: Considerations for graduate preparatory programs in higher education. College Student Journal, 51, 579-584.

UNESCO. (2020). COVID-19 educational disruption and response. https://en.unesco.org/covid 19/educationresponse/

Watson, G., \& Sottile, J. (2010). Cheating in the digital age: Do students cheat more in online courses? Online Journal of Distance Learning Administration, 13(1). https://mds.marshall.edu/eft_faculty 